\title{
Affordances geofísicas das mídias: arte e tempo profundo
}

\author{
Ruy Cezar Campos Figueiredo' \\ https://orcid.org/0000-0001-8339-6634 \\ I - UERJ \\ Rio de Janeiro (RJ). Brasil
}

Resumo: A crise ecológica planetária e suas causas antropogênicas têm feito a geologia emergir em distintos campos do conhecimento a partir do reconhecimento da época geológica Antropoceno. No campo dos estudos de mídia e comunicação, essa emergência se deu a partir de teóricos relacionados à arqueologia e ecologia das mídias como Siegfried Zielinski, Matthew Fuller e Jussi Parikka. O artigo tocará nesse contexto de referências e temas apontando como a arte é reconhecida como pilar, por suas potencialidades epistemológicas, para lidar conceitualmente com as affordances das mídias nas relações de sua ecologia.

Palavras-chave: arte; materialidade; geologia; Antropoceno.

Abstract: Geophysical media affordances: art and deep time - Planetary ecological crisis and its anthropogenic causes made geology emerge in distinct knowledge fields since the acknowledgment of the geological Anthropecene era . In the field of media studies, this emergence is based on media ecology and archaeology thinkers such as Siegfried Zielinski, Matthew Fuller and Jussi Parikka. This paper, accordingly, will address this context of references and subjects highlighting how art is recognized as a pillar for its epistemological potential, to deal conceptually with media affordances in their ecological relations.

Keywords: art; materiality; geology; Anthropocene.

\section{Do tempo profundo na arqueologia das mídias}

Nos últimos anos, as relações entre arte, geologia e tecnologias midiáticas têm sido objeto de produção de conhecimento tanto no campo das artes quanto no campo acadêmico, com exposições e publicações emergindo diretamente em torno do tema. O artigo se desenvolverá observando tal emergência, situando-a a partir de um recorte de conceitos que atravessam a arqueologia das mídias. 
A força propulsora comum da diversidade de abordagens definidoras do que é arqueologia das mídias é "o descontentamento com as narrativas 'canonizadas' da cultura e história das mídias" (HUHTAMO; PARIKKA, 2011, p. 2-3). É com tal sentido que Siegfried Zielinski, um dos primeiros a empregar conceitualmente o termo, afirma-o como uma atividade (Tätigkeit) investigativa e pragmática sobre as camadas de temporalidade constituintes das vias históricas das mídias (ZIELINSKI, 1996).

Com isso, o próprio escopo do que se compreende como mídia vai se expandindo nessa abordagem, incluindo-se na definição de mídia: tentáculos de octópodes, portas, enxames, leis, etc. John Durham Peters (2015, p. 76), para situar pontualmente esse "amplo escopo", afirma que o conceito de mídia é anfíbio: está no entremeio entre organismo e artificio. A zoologia, sem se dar conta, seria uma teoria das mídias: um campo aberto de estudos comparados de mídia, conforme os organismos vivos nos revelam um assustador e comicamente diverso espectro morfológico e funcional de configurações historicamente sedimentadas de soluções para problemas da existência, que os humanos modulam através de técnicas e tecnologia (PETERS, 2015, p. 76). Os organismos vivos seriam um catálogo de aparatos técnicos, repletos de mídias esperando outras mídias as revelarem.

A arqueologia das mídias possui fortes vínculos com a Teoria de Mídia Alemã, que, conforme Stiegert (2008, p. 28), desenvolveu-se em um exercício prolongado de cruzar fronteiras disciplinárias para além das humanidades, a partir do interesse de se confrontar as condições de mediação na biologia, na literatura, na filosofia, na educação, na espiritualidade; chamando atenção para como as técnicas devem ser situadas a partir de questões materiais, temporais e espaciais.

Para o foco do presente artigo, cabe destacar da Teoria de Mídia Alemã a abordagem de Zielinski (2006, p. 5), particularmente quando coloca para o campo do pensamento sobre tecnologias midiáticas, nesse sentido, o conceito de tempo profundo das mídias, apontando para caminhos alternativos, escondidos e pouco usuais de temporalidades midiáticas que direcionarão o pensamento comunicacional para a geologia. Esses caminhos são expostos pelo teórico alemão em análises de experiências propostas por homens como Empédocles ${ }^{1}$, Athanasius Frisher ${ }^{2}$, dentre outros. Zielinski, interessado em técnicas de escuta e visão, escava questões para o pensamento contemporâneo em exemplos que apontam para camadas não lineares e variações no desenvolvimento das mídias.

Fundamentadas nessa conceituação, elas são percebidas como sedimentadas e sobrepostas em relações com a cultura técnica a partir de dobras de tempo e de materialidade (HUHTAMO; PARIKKA, 2011, p. 2-3), em uma contraposição à noção teleológica de evolução de sua evolução, pautada em um suposto progresso natural nas narrativas mais usuais de desenvolvimento tecnológico. Ao direcionar o pensamento comunicacional para o tempo profundo, Zielinski acentua essa contraposição.

1 Zielinski vê no grego (495 a.C. - 435 a.C.) uma significativa fonte de reflexão em torno do conceito de interface.

2 O jesuíta do século XVII é analisado por Zielinski para ter reconhecidas suas contribuições para as áreas de realidade aumentada, técnicas de projeção visual e música combinatória. 
Identificando essa lógica argumentativa, Felinto (2011, p. 46) critica a possibilidade de que o aparecimento da cultura de rede seja resultado natural de um longo percurso teleológico:

Pelejar contra esse naturalismo histórico significa sugerir outras histórias possíveis, inventariar seus aparentes fracassos, professar uma (an)arqueologia que considere, como faz Siegfried Zielisnki (2006), o tempo profundo da mídia (Tiefenzeit der Medien). Nesse que é talvez um dos mais singulares livros de história da mídia escritos recentemente, Zielinski retorna a tempos bem mais distantes que os das tradicionais historiografias da mídia. Como faz Kittler em Vom Griechenland (2001), Zielinski revisita a Grécia clássica na expectativa de produzir um outro tipo de história tecnológica que, em vez de buscar o velho no novo (como vêm fazendo recentemente diversos autores), tenta encontrar o novo no antigo. Nessa abordagem singular, revelam-se, de forma bastante nítida as conexões entre arte e tecnologia, entre imaginação e razão. Afinal, é no campo da artemídia que encontramos o horizonte de experimentação capaz de inaugurar novos usos e interfaces que mais tarde serão incorporados às gramáticas tradicionais dos meios (FELINTO, 2011, p. 46).

O horizonte de experimentação no campo de relações entre arte e mídia, colocado por Felinto ao fim da citação, está relacionado diretamente com o interesse da arqueologia das mídias em se afirmar como atividade investigativa em torno de temporalidades, materialidades e técnicas culturais, munindo-se de uma tradição metodológica especulativa da arte que possibilita que obras e exposições incidam sobre os assuntos que abordam desde pontos de vista peculiares, invocando não apenas (ainda que também) as linhas lógicas de um texto escrito para produzir conhecimento, mas também invocando outras affordances epistemológicas. Essas embutidas nas práticas artísticas contemporâneas, como o uso da gestualidade corporal em diálogo com materialidades, softwares, sistemas, imagens e tecnologias midiáticas.

Delineia-se assim, em termos introdutórios, o que é nuclear para o presente artigo: apontar a emergência de relações conceituais pragmáticas entre arte, tecnologias midiáticas e um tempo profundo. Essas relações abrem afluentes para o fluxo do pensamento comunicacional encarar questões transversais do conhecimento na e sobre a contemporaneidade; para além de uma lógica teleológica, linear e logocêntrica ${ }^{3}$, por uma lógica ativa e pragmática pautada por camadas, sedimentações e dobras de tempo e materialidade ${ }^{4}$.

Será complementar, para esse apontamento, discutir o conceito de affordances em relação às questões que envolvem arte, tecnologias midiáticas e geofísica; compreender

3 O termo logocentrismo é utilizado por Derrida em Gramatologia (1973) para abordar a centralidade do logos no pensamento ocidental. A epistemologia logocêntrica seria aquela que se detém fortemente na razão, em sistemas, leis e nos fatos do conhecimento que dependem primariamente da formulação abstrata dedutiva, relegando o conhecimento adquirido através do sensorial a um status cognitivo inferior e secundário.

4 Ainda que não faça citação e referência direta a Gilles Deleuze em sua obra, traz termos como sedimento e dobra, que são discutidos nos platôs do filósofo francês. 
a abordagem que Jussi Parikka propõe, desde o ponto de vista dos estudos de mídia, para situar o pensamento midiático em relação à materialidade/mineralidade e à crise ecológica planetária em que nos encontramos; destacar como o conhecimento levantado pelas abordagens da arqueologia e geologia das mídias está fundamentado em obras de arte que tocam nos cruzamentos entre materialidade e tecnologias de comunicação.

\section{Arte, affordances e tempo profundo entre a ecologia e a geologia das mídias}

Afetado pela abordagem posta por Zielinski de tempo profundo, Jussi Parikka irá apresentar uma variação desse conceito, invocando diretamente a geologia no pensamento midiático e sua temporalidade não humana, calculada em termos de dezenas de milhares e milhões de anos. Enquanto na metade do século XX ainda éramos uma sociedade dependente de uma lista restrita de materiais como madeira, carvão, tijolo, ferro, cobre, ouro, prata e plásticos, hoje em dia apenas em um microchip podemos encontrar mais de 60 elementos da tabela periódica: 36\% de todo estanho, 25\% de todo cobalto, 15\% de todo paládio, $15 \%$ de todo bronze, $9 \%$ do ouro, $2 \%$ do cobre e $1 \%$ do alumínio vão anualmente para as tecnologias de mídia (PARIKKA, 2015, p. 34). Considerando isso, em Geology of Media (2015), Parikka expande a noção de tempo profundo das mídias em direção à geologia e estabelece para esse encontro dois sentidos que estão relacionados:

1. A geologia se refere às affordances que tornam possível as mídias digitais existirem, tanto como uma materialidade complexa quanto como uma área politicamente mediada de produção e processo: uma materialidade metálica que liga a terra com tais tecnologias de mídia.

2. Temporalidades tais como o tempo profundo são entendidas como uma abordagem alternativa, concretamente ligada aos tempos planetários nãohumanos de decadência e renovação, mas também às obscenidades da ecocrise do Antropoceno - ou, para colocar em uma palavra, Antrobsceno. (PARIKKA, 2015, p. 44, trad. nossa)

Aponta-se, assim, que devemos considerar esse papel duplo do encontro da geologia com as mídias como articulado, primeiramente, a partir de um enquadramento epistemológico das tecnologias de mídia que não só as interprete, mas as perceba, simule, projete e as planeje considerando questões de clima e de meio-ambiente, mais especificamente que considere o quadro das mudanças climáticas no pensamento midiático. Também nos convida a pensar a partir de uma consideração das tecnologias de mídia como efeito colateral que permanecerá no planeta como um traço fossilizado tanto da obsolescência programada de nossa cultura contemporânea de gadgets quanto das infraestruturas massivas que mobilizam o funcionamento das mídias: energia, produção 
de matéria-prima e montanhas de teclados, telas, placas mãe e outros componentes descartados (PARIKKA, 2015, p. 60).

Em relação ao primeiro sentido, usa-se o conceito de affordances para destacar a materialidade mineral que permite às mídias digitais existirem. Materialidade e affordances são conceitos centrais, conforme Parikka (2015, p. 44), para desterritorializar uma lógica humanista das mídias, ensejando abordagens que se colocam para fora do corpo humano e passam a olhar para o não-humano como parte de um emaranhado de agências, um olhar lançado inclusive para a própria Terra.

Apropria-se parcialmente, assim, da definição dada por Gibson (1986, p. 184) para affordance, especialmente no que se refere à percepção corporificada (embodied perception). Os estudos associados ao termo corporificação têm em conta uma perspectiva fenomenológica do corpo que entende a corporalidade a partir da presença, onde corpo seria uma entidade material, enquanto corporificação seria uma referência a um campo metodológico indeterminado e definido pela experiência perceptiva, pelo modo de presença no mundo profundamente afetado e co-constituído por técnicas e tecnologias de mediação.

Gibson elaborou uma teoria que envolve percepção visual e psicologia, sugerindo que as qualidades ou propriedades de um objeto, como sua cor, textura, composição, tamanho, forma e características de massa, elasticidade e rigidez não são o que é percebido quando um objeto é olhado. O que nós percebemos, para Gibson, é o que ele chama de affordances, não exatamente o que o objeto é em si, mas o que ele pode se tornar em uma composição com outros elementos. O termo acabou se tornando comum na área de design, em abordagens como a de Donald Norman, que se voltaram para a experiência do usuário e, de acordo com Fuller (2005, p. 45), em considerações mais amplas em torno da cultura material, mais especialmente no design de interfaces para tecnologias midiáticas.

Ainda que Fuller teça várias críticas à abordagem de Gibson, como devido à sua perspectiva oculoscêntrica, também a valoriza por crer que ela escapa da dicotomia forma-conteúdo e posiciona os objetos e processos midiáticos em uma constelação de inter-relações de formulação materialista, ensejando uma micropolítica do detalhe. Gibson, por exemplo, discutiu aspectos ambientais como oxigênio, gravidade e água para definir tais como affordances que permitem certos movimentos e percepções. Esses elementos são invariáveis e constantes através de toda a evolução da vida animal (GIBSON, 1986, p. 19).

Com um redirecionamento em relação ao seu propósito material e histórico, essa noção de affordance também pode ser mobilizada em uma abordagem da teoria e ecologia das mídias, como o faz Fuller ao se calcar no termo affordances para afirmar a relevância de uma agenda de pesquisa pautada na ênfase sobre a circulação de energias e outras materialidades, entendidas como affordances. Destaca-se, assim, como as mídias estão misturadas ou são atravessadas por calor, materiais e por uma inteligência que, em ritmos particulares, fornece os meios para a mistura e conservação de modos, efeitos, dinâmicas relacionais e potencialidades mutantes que ensejam os processos dos agentes e procedimentos midiáticos: 


\begin{abstract}
A ecologias das mídias como pesquisa sobre as affordances está interessa no que capacita e no que incapacita, oferendo não uma visão sobre os objetos, mas sobre suas potencialidades. Fuller nos inspira com a questão: e se nós pudéssemos dar um passo material em termos de adotar literalmente uma ecologia das mídias, talvez de maneiras que enfatizem o continuum de natureza das mídias, mas também que estenda a ideia de affordances para temas como desperdício e descarte? Quanto às materialidades das mídias, talvez elas comecem bem antes das mídias serem mídias. As tecnologias das mídias podem ser entendidas como uma longa história de experimento com diferentes materiais - de placas de vidro aos químicos, do selênio para o silício, da columbita-tantalita a raros minerais terrestres, do ácido sulfúrico à gutta percha à seda de goma-aca - em processos de cristalização, ionização etc (PARIKKA, 2012, p. 97, trad. nossa).
\end{abstract}

Por incorporarem as materialidades e explorarem as affordances dos objetos de maneiras conceitualmente especulativas e experimentais, com capacidade de falar corporificadamente sobre a materialidade das realidades do hardware e software e das infraestruturas que possibilitam as mídias existirem, as obras, práticas e metodologias artísticas são valorizadas também nos estudos de Fuller (2005, p. 74) sobre as ecologias das mídias. Nesses métodos, uma longa cascata de relações que são recorrentes na história das práticas artísticas estão presentes, abrindo possibilidades para que, por vias metodológicas, processos de renovação no fazer-pensar dos estudos de mídia e comunicação sejam desencadeados.

Parikka (2015, p. 25) aponta, nessa correlação entre pensamento e práticas artísticas valorizada pela arqueologia e ecologia das mídias, que ocorre uma virada geopolítica para os estudos de mídia ao se considerar o fato de que os dados digitais são situados em um território legal e material e que se pode falar de uma geofísica da informação, onde a arte entra com seu engajamento exploratório de affordances não logocêntricas. Uma abordagem geológica sobre as mídias constituiria uma ponte conceitual entre materiais de tipo químico ou metálico e o impacto cultural das tecnologias das mídias, como variação dos discursos em curso sobre a economia política digital global. Trata-se do ensejar de uma perspectiva mais geocêntrica sobre a cultura digital, que emerge dos estratos da Terra envolta por cabos ópticos e hardwares.

Um projeto de arte que bem dialoga com o primeiro sentido que Parikka atribui à noção de tempo geológico das mídias é The Crystal World (2012), que consistiu em uma exposição e laboratório aberto, desenvolvido por Martin Howse, Ryan Jordan e Jonathan Kemp em Londres e Berlim, explorando a residualidade material de tecnologias digitais por meio de processos químicos que decompunham e recompunham aparatos técnicos, investigando formas desses se relacionarem e se fossilizarem com a Terra.

Via-se: placas mães sendo corroídas e misturadas com formações rochosas dispostas no espaço expositivo em meio a tubos de laboratório; fragmentos de computadores com 
cristais crescidos sobre eles por meio de processos químicos que posicionam o cristal como uma chave conceitual através da qual a base metal e mineral das máquinas é escavada; hard drives afetados por ácido sulfúrico; e, especialmente, Earthboot, um computador de terra, em uma configuração experimental de hardware que permite ao sistema operacional se inicializar com base em um dispositivo USB customizado e diretamente conectado ao solo arenoso. Além disso, uma publicação sem assinatura de autor com mais de 500 páginas, chamada The Crystal World Reader and Manual of Speculative Apparatus, especula questões em torno do futuro fóssil de nosso planeta a partir da geologia de aparatos tecnológicos. Diz o texto anônimo:

\begin{abstract}
Os laboratórios de pesquisa experimental The Crystal World visam investigar as várias de/re-cristalizações do digital através de sua eletrônica redundante e substratos geológicos. Imitando os geralmente perigosos processos tomados na recuperação de minerais raros e preciosos por desprivilegiados, The Crystal World busca minar em meio aos suportes venenosos de um mundo de distopia sintetizada, dando um novo proposito a esse mundo com intervenções através da experimentação com a formação de novas geologias cristais, visando gravar tanto distorções psicogeofísicas não esperadas quanto contingências de nossos ciclos cristalinos contemporâneos (THE CRYSTAL WORLD, 2012, p. 2, trad. nossa).
\end{abstract}

Para Parikka (2015, p. 75), encontramos nesse projeto o argumento de que as máquinas não se encontram mortas, posto que elas se sustentam de estratos geofísicos, de traços arcaicos de uma vida passada, ou em outras palavras, elas apresentam a reterritorialização dos estratos geológicos em tecnologias midiáticas e na mineralização dessas tecnologias, rastreando seu tempo profundo a partir de cristalizações e descristalizações.

Para avançarmos na compreensão do segundo sentido supra-citado de tempo profundo das mídias proposto por Parikka (relacionado às questões que o Antropoceno coloca para o pensamento sobre as mídias), creio que a instalação artística The Sound Of (2007-2008), de Katie Peterson, é relevante para facilitar o entendimento, bem como apoia o esclarecimento da abordagem aqui referenciada sobre o conceito de affordance. Uma exploração geofísica desse conceito pode nos conectar com estratos, com a dimensão geológica do tempo e com as implicações humanas no clima do planeta.

A artista Katie Peterson conecta concretamente infraestrutura tecnológica de transmissão com paisagens sonoras do geofísico em crise ecológica, ao criar uma linha telefônica para se telefonar a uma geleira na Islândia, por meio de um microfone submerso em um lago. Na obra de Peterson, podia-se telefonar para um dado número desde qualquer lugar do mundo e assim se escutar ao vivo os sons da geleira derretendo. $\mathrm{O}$ trabalho nos afeta acusticamente para a transformação que o atual modo de vida provoca na geologia da Terra. Aqui, para Parikka (2015, p. 70), a mídia de transmissão se torna também um dispositivo de mediação a uma outra experiência de temporalidade da crise ecológica que vivemos, ainda que o tema das mudanças climáticas em si já esteja recorrentemente representado. 
No segundo direcionamento apontado por Parikka para seu modo de entender o tempo profundo das mídias há, portanto, uma ênfase na relacionabilidade entre a crise ecológica em que o planeta se encontra e que é discutida na geologia a partir do conceito de Antropoceno. Como será visto no próximo tópico, Haraway (2016) e Parikka (2014), dentre outros, questionam essa nomenclatura e propõem outras. Independente da nomenclatura, o conhecimento de todas as áreas científicas é hoje encarado por escalas de tempo que são orientadas por longas durações não humanas devido a uma crise ecológica que pode fazer perceptíveis e inteligíveis ao humano transformações que antes operavam geologicamente em escalas de tempo não inteligíveis.

Esse encontro do não humano com as humanidades, por exemplo, marca o que seria a virada geológica do pensamento crítico e que possui um valor específico ao forçar as ciências humanas, dentre as quais a comunicação, a encarar um espectro mais amplo de mundos materiais, considerando o meio-ambiente e sua relação com a cultura midiática contemporânea para além de uma separação entre sujeito e objeto refletida na separação entre humano e natureza. Daí se deduz a capacidade da arte como experiência que tensiona fronteiras da corporificação e afetividade do presente e suas políticas ecológicas e epistemológicas.

\section{Antrobsceno}

O desígnio formal do reconhecimento de que nos encontramos em uma época geológica que não mais o Holoceno se deu no $35^{\circ}$ Congresso Internacional de Geologia realizado na Cidade do Cabo, África do Sul, em 2016. O nome que tem se firmado e popularizado para essa nova época geológica é Antropoceno, um termo que acaba demonstrando que a geologia não se refere exclusivamente ao solo sob nossos pés, mas também à realidade de crise climática na contemporaneidade, bem como à constituição de nossa experiência técnico-cultural. Como marco fundamental do conceito, cunhado na década de 1980 pelo ecologista Eugene Stormer, está o fato de que o agente humano (genérico) é apontado como o causador de mudanças geofísicas de grandes proporções, considerando que suas ações modificaram os ecossistemas, as rochas, o clima, as águas e os processos simbióticos da vida no planeta.

Parikka (2014, p. 46) lembra, em seu viés mídia-arqueologista, que a noção de Antropoceno foi precedida pela invenção conceitual da era Antropozoica, da qual se destaca como um formulador o italiano Antonio Stoppani, na década de 1870, já enfatizando os estratos da terra como afetados por tecnologias humanas e pelas ruínas de suas invenções. Voltando para o século XXI, Haraway nos situa:

Em 2008, muitos cientistas ao redor do mundo tinham adotado um termo ainda não oficial, mas crescentemente indispensável; uma miríade de projetos de pesquisa, 
performances, instalações e conferências nas artes, ciências sociais, humanidades, todos achando esse termo mandatório em seu nomear e pensar, por encarar tanto as extinções aceleradas através das táxons biológicas quanto a imiseração humana e multiespécies aos custos da Terra (HARAWAY, 2016, p. 46, trad. nossa).

Em seus textos recentes, Donna Haraway tem discutido a importância de se pensar alianças para estar em meio a essa época que ela se recusa a nomear apenas de Antropoceno. Haraway propõe, multiplicando as vias de se pensar esse contexto, outros termos como Plantataçõesceno ${ }^{5}$, Capitalosceno ${ }^{6}$ e Chthuluceno ${ }^{7}$. O argumento base para a crítica de Haraway e de outros, como Viveiros de Castro e Isabelle Stengers, é de que uma espécie humana geral representada no Homem com H maiúsculo não estabeleceu as condições para a crise climática atual e que a definição do "Antropo" como agente das mudanças climáticas é:

uma repetição quase engraçada da grande Aventura fálica humanizadora e modernizadora, onde o homem, feito na imagem de um deus desaparecido, toma os superpoderes com seu sotaque sacro-secular, apenas em trágica detumescência, mais uma vez. Autopoiético, o homem que faz a si mesmo desceu mais, dessa vez em falha sistêmica trágica, transformando os sistemas biodiversos em desertos arrasados de águas-vivas urticantes e tapetes viscocos. Tampouco foi o determinismo tecnológico que produziu a Terceira Era do Carvão (HARAWAY, 2016, p. 47, trad. nossa).

Haraway não pretende, com a discussão sobre como se nomear essa época, chegar a um nome único e definitivo: ela acredita que cada nome pode ser usado para se direcionar a aspectos lacunares na compreensão conceitual desses tempos. Nesse sentido e pensando o reconhecimento dessa época geológica desde o campo dos estudos de mídia, Jussi Parikka propõe uma outra nomenclatura: Antrobsceno. Resumidamente, a obscenidade inerente a essa época geológica (e o próprio gesto de conceituá-la) ganha um caráter autoexplicativo, porém direcionado à consideração da insustentabilidade da cultura tecnológica contemporânea e suas redes infraestruturais. Para esclarecer sua proposição, ele recorre prontamente em seu texto às obras de arte iMine (2009) e Tantalum Memorial (2011).

5 Em inglês, plantationoscene, que enfatiza as relações entre o colonialismo e as causas antropogênicas das mudanças climáticas, a partir de uma ênfase na transformação nas fazendas, pastos e florestas em plantações extrativistas pautadas no trabalho escravo, na monocultura, na produção global de carne para consumo, agronegócio e efeitos da morte de espécies devido à devastação de ecossistema para produção de bens como o óleo de palma.

6 Abordagem que pensa a época geológica mais a partir das transformações envolvendo o mercado e o modelamento do mundo a partir de mercadorias desde os séculos dezesseis e dezessete até o presente, com uma ênfase nas práticas extrativistas.

7 Haraway pensa esse termo a partir da aranha Pimoa cthulhu, enfatizando o poder da Terra como tentacular, associando-se a abordagem de Gaia de Eduardo Viveiros de Castro e Déborah Danowski, assim como invocando toda uma variedade de referências mitológicas ancestrais relacionadas à Terra como dotada de agência formada por alianças multiespécies. 
Esse pronto recorrer chama atenção sobre como práticas artísticas têm atravessado o pensamento dos estudos de mídia.

As práticas e obras citadas por Parikka nos livros Geology of Media (2015) e Anthrobscene (2014) levantaram questões trazendo conhecimento por meio de experiências corporificadas e afetivas da ambientalidade que marca nosso tempo geológico, uma época que deve ser compreendida e definida por sua condição tecnológica, ou mais, pelo emaranhamento entre a ecologia e questões tecnológicas, noções de subjetividade e agência não humana. O Antrobsceno acaba demonstrando que a geologia não se refere exclusivamente ao solo sob nossos pés, mas que é constitutiva de nossas realidades midiáticas, tecnológicas, ambientais.

\begin{abstract}
A geologia é desterritorializada nas formas concretas em que o metal e os minerais se tornam móveis, permitindo a mobilidade tecnológica: as palavras de Benjamin Bratton não poderiam ser melhores, quando ele escreve sobre como carregamos pequenos pedaços da África em nossos bolsos, referindo-se ao papel, por vez, da columbita-tantalita nas tecnologias de mídia (PARIKKA, 2017, p. 178, trad. nossa).
\end{abstract}

E é exatamente sobre pedaços da África que armazenamos em nossos bolsos que trata o game-art iMine (2009), que pode ser baixado na Apple Store para iPhone. Trata-se de um game intencionalmente difícil e simples, em que o jogador deve, ao invés de meramente tocar na tela, movimentar-se com o telefone em gestos repetitivos de mineração, realizados por um avatar sob a mira de uma arma. O tema é a vida difícil de um minerador africano no processo de extração de tântalo, metal essencial para a produção de iPhones e smartphones no geral.

Trabalho, materialismo e mineralidade "antrobscênica" se encontram no campo de estudos de mídia a partir dessa obra de arte que Parikka (2015, p. 92) coloca em diálogo com reflexões sobre corpo e mídia postas pelo teórico das mídias Friedrich Kittler em seu livro Aufschreibesysteme 1800/1900 (1985). Mais especificamente, ao discutir as relações entre corpo e poder desde uma perspectiva material, Parikka refletirá sobre o corpo do trabalhador (cuja gestualidade é o mote do game) como uma superfície que registra os efeitos e afetos das mídias. Também refletirá sobre outra superfície evidente no game, um outro corpo, mais especificamente, o próprio corpo da Terra:

O minerador em iMine é mapeado como parte de um fluxo abstrato de preços minerais e comércio global, contrastado contra os atuais preços de ferro, tântalo, tungstênio e ouro. O jogo articula os processos repetidos de mineração como parte de valorações abstratas que oferecem uma base financeira para o comércio de minerais, bem como luta contra a falta de percepção da parte das últimas décadas de teoria das mídias que acreditava que a telemática poderia nos libertar do trabalho chato e repetitivo e assim liberar nossas capacidades cognitivas lúdicas, transformando a redundância em informação (PARIKKA, 2015, p. 91, trad. livre). 
Enquanto game, iMine nos recorda (com uma interface simples e uma jogabilidade exaustiva dada pela relação gestual com o iPhone) que a própria materialidade do aparato é composta por minerais e químicos e que tanto o corpo do minerador quanto o corpo da Terra são superfícies afetadas pelas tecnologias da informação. Parikka (2015, p. 94) defende tais corpos como objetos epistêmicos dos estudos de mídia, conforme registram, no mercado financeiro global, a materialidade da produção da tecnologia de informação em seus sistemas (pulmonares, nervosos, tecno-orgânicos, etc.) e nos estratos geológicos. iMine, por fim, anuncia como os hardwares são feitos de materiais que vêm da Terra e como as condições de produção de tecnologia digital se dão em duras condições de trabalho.

Dialoga diretamente também com a obra de arte Tantalum Memorial (2009), de YoHo. Percebe-se nessa instalação artística uma dimensão geopolítica mais ampla sobre os afetos e efeitos do hardware de dispositivos móveis e sua dependência do mineral tântalo. A obra bem corporifica a emergência desse tema desde uma abordagem da arqueologia das mídias, lançando um foco nesse aspecto que inclui a geofísica na compreensão da materialidade das tecnologias digitais.

A obra vetoriza temas como guerra na África, imigração e refúgio a partir da demanda pela mineralidade que permite a produção contemporânea de smartphones e que está por trás de uma diversidade de atuais conflitos armados no Congo, país que é detentor das maiores reservas de columbita-tantalita e uma das maiores reservas de cobalto do mundo. A instalação artística é construída com uma central de comutação telefônica eletromagnética de 1938: os comutadores são reanimados em sua sonoridade mecânica, controlados por um computador que rastreia as ligações de telefone de uma rede de telefonia social projetada pelos artistas em colaboração com um programa de rádio congolês em Londres. A rede da instalação artística telefona para ouvintes congoleses, toca uma mensagem e os convida para gravar um comentário acerca do tema da instalação, pedindo-os para passarem adiante a mensagem para um amigo, utilizando um número de telefone. A rede, chamada de Telephone Trottoire, é inspirada em uma prática tradicional congolesa de passar notícias e fofocas em esquinas para se evitar censura estatal. As ligações se tornam memoriais para as mais de quatro milhões de pessoas que morreram nas guerras que ocorreram no Congo desde 1998, que são conhecidas como Coltan Wars e que motivaram a busca por refúgio de muitos dos imigrantes potenciais ouvintes do programa de rádio. Quando em exibição, os visitantes da instalação puderam acompanhar o processo de ligação das chamadas em um monitor que se encontrava próximo e puderam ouvir as mensagens que estavam sendo passadas por meio de headphones. Tal obra carrega em sua experiência o próprio conceito de materialidade das mídias na abordagem dessa arqueologia geológica das mídias:

A materialidade das mídias não está contida nas máquinas, mesmo que as máquinas contenham um planeta. As máquinas são mais como vetores através 
dos quais estão contidas geopolíticas de trabalho, recursos, escavações planetárias, produção energética, processos naturais de fotossíntese para mineralização, químicos e outras rebordosas do lixo eletrônico (PARIKKA, 2015, p. 139, trad. nossa).

Esse pensamento de Parikka se evidencia também no texto poético que produziu para o vídeo White Mountain (2015), da artista Emma Charles, apresentado em São Paulo de novembro a fevereiro de 2018 na exposição Campos de Invisibilidade, no Sesc Belenzinho, com curadoria de Cláudio Bueno e Lígia Nobre e minha assistência curatorial.

O texto do finlandês é narrado, no filme de Emma Charles, por uma voz feminina, sobrepondo imagens de um data center que se encontra no interior de uma formação rochosa em Estocolmo e que previamente era um bunker civil da Guerra Fria, abrigando hoje os servidores de projetos como Wikileaks e Pirate Bay. As tecnologias digitais e sua infraestrutura são enquadradas, no vídeo, evidenciando sua relacionabilidade com o entorno e interior geológico do data center, dotado de distintas camadas de tempo implicadas em diversas questões geopolíticas como a Guerra Fria, a pirataria digital e segredos de Estado revelados ao público:

A Terra sempre carregou consigo uma história secreta, escondida debaixo de sua superfície. O lado de fora, ruidoso, era um tipo de distração, feita para camuflar o que estava abaixo da pele. Uma história de vibração, som, de movimento visual cravado nos estratos que nós egoisticamente pensamos ter descoberto. Linhas feitas de cobre escutam nos sussurros naturais dos pássaros; elas escutam a radiação eletromagnética; elas escutam as vibrações. A corrente que correu através da terra a eletrificou. Os cabos invisíveis que cobrem sua superfície conduziram as primeiras mensagens em escala planetária para nenhuma pessoa em particular. O que se pensava ser uma cidade artificial, o underground transformou em habitat natural. Um mundo geofísico de transmissão, calculo e armazenamento. Fantasias do hidrocarboneto transformadas em vida secreta dos dados que estão enterrados como os fósseis costumavam estar (CHARLES, 2015, trad. nossa).

Enseja-se, assim, discussões que são instrumentais na articulação de diferentes escalas de tempo e de uma compreensão de um geológico que se expande para questões da temporalidade da realidade política, econômica, cultural do digital e do tecnológico e, mais especificamente, para melhor compreendermos as manifestações do Antrobsceno. As questões de estética, de percepção e sensação, passam a se desdobrar diferentemente quando se leva em consideração essas escalas de tempo não humanas e o potencial especulativo das práticas artísticas são fundamentais para que se avance na compreensão das dimensões possíveis de uma abordagem material sobre as mídias que inclua sua mineralidade e sua posição no Antrobsceno, alargando o escopo de seu enquadramento ecológico. 


\section{Conclusão}

A partir de um recorte de fundamentos da arqueologia das mídias, apontou-se primeiramente para a existência de uma diversidade de interesses e abordagens conceituais propondo variações de compreensão sobre processos técnico culturais e de mediação através dos tempos, para além de uma perspectiva teleológica. Desse contexto emerge o interesse pelo tempo profundo, com Zielinski pensando, por exemplo, sobre interface no contexto da digitalidade a partir de concepções de interface em tempos anteriores à Cristo.

Jussi Parikka, dialogando com a ecologia das mídias de Matthew Fuller, aprofundou esse tempo profundo em direção à geologia, acompanhando um movimento que se dava desde meados do fim da década passada em práticas de arte e tecnologia. Parikka enfatiza, por um lado, o caráter mineral dos aparatos tecnológicos e a energia material que sustenta as redes de telecomunicação; por outro lado, o contexto do Antropoceno e a participação das tecnologias de comunicação (e de uma certa negligência de seus teóricos) nessa crise, derivando-se daí a variante conceitual Antrobsceno. Esses dois caráteres estão relacionados entre si.

A discussão, pode-se dizer, é mesmo urgente, sendo importante que mais pesquisadores do campo comunicacional adquiram engajamento na reflexão em torno dessa dimensão ecológica das mídias na contemporaneidade. A arqueologia das mídias, da qual a proposição de geologia das mídias de Jussi Parikka é também uma variante, enfatiza as práticas artísticas como uma pista metodológica sobre como se fazer isso e o destaque que se buscou dar a essa ênfase é também uma expectativa de desdobramentos artístico-investigativos ao se seguir essa pista.

Ruy Cezar Campos Figueiredo é doutorando em Comunicação na Universidade do Estado do Rio De Janeiro - UERJ, mestre em Artes pela Universidade Federal do Ceará - UFCE.

czr.campos@gmail.com

\section{Referências}

THE CRYSTAL WORLD reader and Manual of Speculative Apparatus. 2012. Disponível em: [http:// xxn.org.uk/The_Crystal_World_Reader_v.1.pdf]. Acesso em: 03 jun. 2017.

FELINTO, E. Em busca do tempo perdido. O sequestro da história na cibercultura e os desafios da teoria da mídia. MATRIZes, São Paulo, v. 4, n. 2, 2011.

FULLER, M. Media Ecologies: Materialist Energies in Art and Technoculture. Cambridge, Massachusetts: MIT Press, 2005. 
DERRIDA, J. Gramatologia. Trad. Miriam Schnaiderman e Renato J. Ribeiro. São Paulo: Perspectiva, 1973.

GIBSON, J. J. The Ecological Approach to Visual Perception. Boston: Houghton-Mifflin Company, 1986.

HARAWAY, Donna. Staying with the Trouble: Making Kin in the Chthulucene. Durham: Duke University Press, 2016.

HUHTAMO, E. PARIKKA, J. Media Archaeology: approaches, Applicattions and Implications. Berkeley: University of California Press, 2011.

KITTLER, F. Aufscreibesysteme 1800/1900. Munique: Editora Wilhelm Fink, 1985.

PARIKKA, J. Deep Times and Media Mines. A Descent into the ecological materiality of technology. In: General Ecology: The New Ecological Paradigm. Erich Hörl (ed.). London: Bloomsburry Academic, 2017, p. 169-193. Press, 2015.

A geology of media. Electronic Mediations, vol. 46. Minneapolis: University of Minnesota The Anthrobscene. Minneapolis: University of Minnesota Press, 2014.

New materialism of dust. In: Artnodes, no. 12. P. 83-88. Barcelona: Universit Oberta de Catalunya, 2012.

PETERS, J. D. Marvelous Clouds: towards a philosophy of elemental media. Chicago: University of Chicago Press, 2015.

SIEGERT, B. Cacography or communication? Cultural techniques in German media studies. Trad. Winthrop-Young G'. In: Grey Room 29, 2008, p. 26-47.

ZIELINSKI, S. Deep Time of the Media: Towards an Archaelogy of Hearing and Seeing by Technical Means. (trad. inglesa de Archäologie der Medien: Zur Tiefenzeit dês technischen Hörens und Sehens). Cambridge: MIT Press, 2006.

Media Archaeology. Ctheory.net. 7 de nov, 1996. Disponível em: <http://ctheorynet/articles. aspx?id=42>. Acesso em: 18.jul. 2018.

\section{Vídeo}

CHARLES, E. White Mountain. Nova York, 2015. 